\title{
Design and Performance of a Hybrid-Electric Fuel Cell Flight Demonstration Concept
}

\author{
Nicholas K. Borer, ${ }^{1}$ Steven C. Geuther, ${ }^{2}$ Brandon L. Litherland, ${ }^{3}$ Lee Kohlman ${ }^{4}$ \\ NASA Langley Research Center, Hampton, Virginia 23681, USA
}

\begin{abstract}
As electric powertrain and propulsion-airframe integration technologies advance, airborne electric propulsion concepts appear to be on the cusp of disrupting or transforming aviation markets. One of the many challenges to this transformation lies within the onboard energy storage and generation technologies. State-of-the-art battery technology is heavy and lacks support infrastructure; purely combustion-based solutions to electrical power generation suffer from increased inefficiency as compared to a traditional combustion powertrain. This paper explores another alternative: a hybrid-electric, solid oxide fuel cell power system. This power system reforms traditional fuels to feed fuel cells that generate electrical power for the aircraft electric powertrain. A representative power system is designed based on the requirements for NASA's X-57 Mod II electric flight demonstrator platform, and is shown to exceed system feasibility goals of $300 \mathrm{~W} / \mathrm{kg}$ and $60 \%$ efficiency in at least one configuration. The hybrid-electric fuel cell power system is shown to be competitive with the range performance of a combustion-based power architecture and comparable in mission energy cost to a battery-electric power system.
\end{abstract}

\section{Nomenclature}

$\begin{array}{ll}\text { AFDC } & =\text { U.S. Department of Energy Alternative Fuels Data Center } \\ C G & =\text { Center of Gravity } \\ D A C & =\text { Design/Analysis Cycle } \\ D E P & =\text { Distributed Electric Propulsion } \\ \text { FLOPS } & =\text { Flight Optimization System (NASA aircraft mission analysis tool) } \\ G G E & =\text { Gallon of Gasoline Equivalent energy } \\ H E X & =\text { Heat Exchanger } \\ K C A S & =\text { Knots (nautical miles per hour) Calibrated Airspeed } \\ K T A S & =\text { Knots (nautical miles per hour) True Airspeed } \\ L H V & =\text { Lower Heating Value } \\ M C P & =\text { Maximum Continuous Power } \\ M S L & =\text { Mean Sea Level } \\ \text { FUELEAP } & =\text { Fostering Ultra-Efficient, Low Emitting Aviation Power (NASA project) } \\ \text { SCEPTOR } & =\text { Scalable Convergent Electric Propulsion Technology Operations Research (NASA project) } \\ \text { SOFC } & =\text { Solid Oxide Fuel Cell }\end{array}$

\section{Introduction}

Aviation is continually evolving to meet the needs driven by markets in transportation, observation, hobby use, and more. These needs are established in a dynamic, competitive landscape, where advances in technology can bring favor to previously undesirable solutions or cause formerly favored solutions to wane in preference. Recent advances in electric powertrain technologies, coupled with advanced aircraft configurations, have the potential to disrupt traditional airborne propulsion architectures in certain markets [1]. The current drawbacks of airborne electric propulsion, particularly related to energy storage and energy distribution infrastructure, may slow or limit adoption of

\footnotetext{
${ }^{1}$ Principal Investigator/Aerospace Engineer, Aeronautics Systems Analysis Branch, MS 442, AIAA Senior Member.

${ }^{2}$ Aerospace Engineer, Aeronautics Systems Analysis Branch, MS 442.

${ }^{3}$ Aerospace Engineer, Aeronautics Systems Analysis Branch, MS 442.

${ }^{4}$ Aerospace Engineer, Aeronautics Systems Analysis Branch, MS 442, AIAA Member.
} 
this technology. These drawbacks have thus far limited market penetration in all but the smallest vehicle classes. Current approaches to airborne electricity generation revolve around storage of the energy in batteries onboard the aircraft, which greatly limits range and endurance, or generation of electricity by combustion of stored hydrocarbon fuel as part of a hybrid-electric architecture, which suffers from mass and efficiency challenges.

Borer [1] outlined these approaches and recommended pursuit of an additional option to the portfolio of solutions available to store energy for airborne electric propulsion. Borer proposed the use of a hybrid-electric solution that generates electricity primarily from a Solid Oxide Fuel Cell (SOFC) fed from an onboard fuel reformer, which converts heavier hydrocarbons into products suitable to be consumed by the SOFC. To be viable, this power system needs to operate at a specific power level of at least $300 \mathrm{~W} / \mathrm{kg}$ and an efficiency of $60 \%$, referenced to the lower heating value (LHV) of the stored fuel. These characteristics represent significant advances in the state-of-the-art for hybrid-electric SOFC architectures - a recent National Academies report indicated that such architectures are capable of a specific power of $100 \mathrm{~W} / \mathrm{kg}$ and an efficiency of 30-40\% [2]. More recent research suggests that higher specific power and efficiency levels are achievable [3].

This paper is one of a number of concurrent papers related to NASA's Fostering Ultra-Efficient, Low-Emitting Aviation Power (FUELEAP) project. The authors present a detailed application of a hybrid-electric, heavy-fuel, SOFC power system developed under FUELEAP. Specifically, this paper describes the integration of a $120 \mathrm{~kW}$ power system in place of the battery system used on NASA's X-57 "Maxwell" distributed electric propulsion (DEP) technology flight demonstrator. Section II provides background on FUELEAP and the X-57 program. Section III describes the integration of the hybrid-electric SOFC power architecture onto the X-57 and provides performance estimates for two different design spirals, as well as comparison to gasoline-fueled and battery-powered alternatives. Finally, Section IV summarizes the results of this research. Other companion papers include: a more detailed description of the power system design [4], electrical integration of this power system into the X-57 [5], thermal cycle testing of SOFC hardware to assess suitability for aviation operations [6], system safety analysis of the FUELEAP X-57 demonstrator concept [7], and the use of model-based systems engineering frameworks to aid in the development of future demonstrator concepts [8].

\section{Background}

In 2016, a NASA-funded study outlined many of the challenges associated with the advent of airborne electric propulsion [9]. At the time, the major challenges identified were: (1) specific energy of the energy stored onboard the aircraft, (2) refueling/energy support infrastructure, and (3) certification. This study surveyed a number of aircraft as demonstrator candidates for a new type of hybrid-electric power system - one that generated electricity primary from a SOFC fed from a reformed hydrocarbon fuel stream. This new power system had the potential to be up to twice as efficient as traditional combustion-based concepts, and it used an onboard energy source with $60 \mathrm{x}$ better specific energy content than state-of-the-art batteries. The results indicated that this hybrid-electric SOFC system could feasibly be integrated into a near-term flight demonstrator.

\section{A. FUELEAP}

The first two themes from the 2016 study (specific energy and infrastructure challenges) are expanded upon in Borer's companion paper [1], which includes a comparison of relevant power systems for markets that will be likely early adopters of airborne electric propulsion. Borer highlights the tradeoff between the specific power of the energy generation system onboard the aircraft and the mass of the energy storage. However, this approach does not necessarily seek mass parity across the powertrain + energy generation + energy storage system, nor does it seek net energy use parity; rather, it recognizes that systems that are heavier or use more energy may still have lower operating costs and emit fewer system-level emissions. Overall, Borer's paper estimates that short-endurance ( 30 minute) battery-electric concepts are viable with a combined specific power (maximum continuous power divided by the sum of powertrain, energy generation, and energy storage mass) of $200 \mathrm{~W} / \mathrm{kg}$ or greater. Maintaining this specific power ratio at the longer endurances available with combustion-based systems forms the basis of a combined specific power and efficiency target for the hybrid-electric SOFC system.

The analysis referenced above was performed in support of establishing the feasibility goals for a recent NASA project, FUELEAP, which was one of five projects selected under NASA's Convergent Aeronautics Solutions (CAS) project in 2016 [10]. NASA CAS projects are established to identify feasibility barriers to a particular problem ("big question") in aviation, and to show how a particular transformative concept can overcome these barriers. FUELEAP's "big question" is: "How can we enable near-term, widespread adoption of airborne propulsion and power architectures that yield compelling emissions, efficiency, and performance benefits without requiring a major investment in infrastructure, certification, or energy storage?" The stated goal for the FUELEAP project is to "establish the 
feasibility of an integrated heavy-fuel hybrid-electric SOFC power system as a transformational source of aviation power." The feasibility objectives, supported by the companion paper for this power system [1], are:

- Power output $>75 \mathrm{~kW}$ - necessary for primary power for light aircraft and secondary/auxiliary power for large aircraft,

- Installed specific power $>\mathbf{3 0 0} \mathrm{W} / \mathbf{k g}$ - otherwise too heavy for most aviation applications,

- Fuel-to-electrical efficiency of $>\mathbf{6 0} \%$ using "pump gas" - cuts fuel use and carbon emissions by 30 $50 \%$ compared to today's combustion engines while using existing fuel distribution infrastructure.

To meet these goals, FUELEAP is evaluating a power system architecture that leverages the technology convergence of lightweight, high-efficiency SOFC components, high-yield fuel reformation approaches, and hybridization. A simplified system architecture diagram is shown in Fig. 1. Here, hydrogen harvested from diesel fuel in a fuel reformer to generate electricity in a pressurized fuel cell. The carbon monoxide generated during the reformation process is used to produce additional electricity in the fuel cell, and unspent fuel from the reformer is "burned" (catalyzed) to add additional energy to the exhaust flow. The exhaust is expanded through a turbine that pressurizes the intake air and operates a small generator. More details on the development of this architecture are discussed by Stoia et al. [3][4].

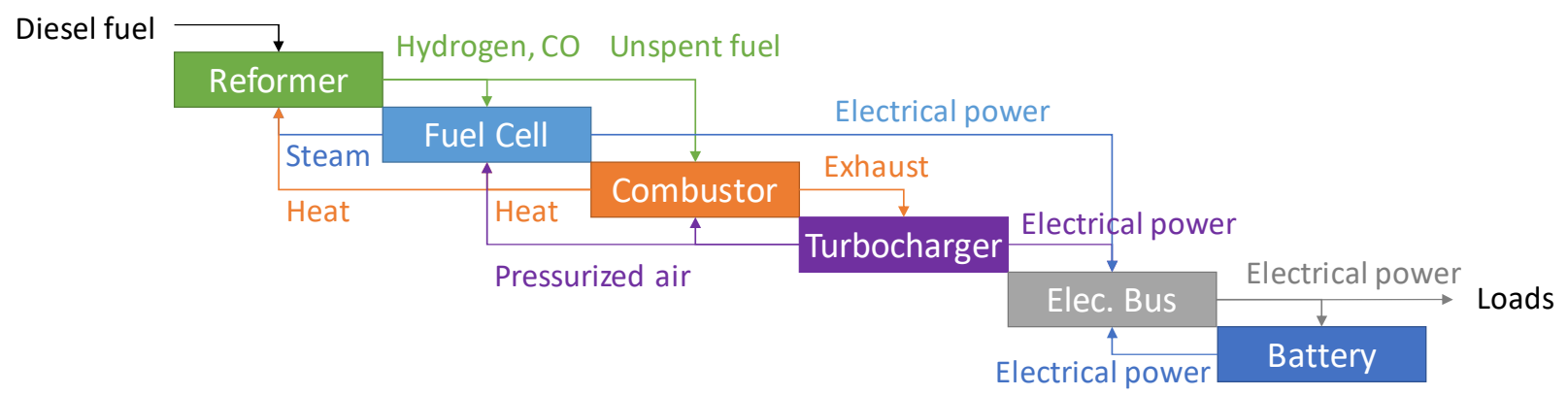

Fig. 1 Heavy-fuel, hybrid-electric SOFC power system architecture used for FUELEAP.

The FUELEAP project is broken into three major tasks to establish the feasibility of this power system. First, stateof-the-art SOFC hardware is tested in flight-like environments, including: effects of thermal cycling, response to different fuel utilization and loading to high current densities, operation at above ambient pressure, and response to off-nominal conditions. Some of this testing is discussed by Goldsby et al. [6], and additional tests will continue until the end of the project. Second, the team conducted detailed design, performance, and safety analysis of a system suitable for generation of electrical power for primary propulsion on an aircraft. This was the bulk of the design effort and is described in this paper. Third, the team is developing the conceptual design of a system for auxiliary power generation. This study is ongoing, and has yet to be published.

To perform the second task (detailed design of a primary power system), the team needed to select a candidate demonstrator platform. The 2016 study considered the retrofit of five different aircraft, powered by gasoline Otto cycle engines or, in one case, a heavy-fuel Brayton cycle engine [9]. In all cases, significant retrofit activity would be required to adapt an airborne electric propulsion system for primary generation of thrust. This was a challenge - to conduct a realistic detailed design study, FUELEAP required a credible airborne electric propulsion system. The design of such a system would take resources away from technology development associated with the FUELEAP hybrid-electric SOFC architecture. As such, the team looked to other, purpose-built aircraft and flight demonstrators for airborne electric propulsion, particularly those with detailed data available to conduct a more in-depth study. After careful consideration, the FUELEAP team elected to develop a power system suitable for NASA's all-electric X-57 "Maxwell" flight demonstrator.

\section{B. $\mathrm{X}-57$}

NASA's Scalable Convergent Electric Propulsion Technology Operations Research (SCEPTOR) project is developing the X-57 "Maxwell" flight demonstrator, which aims to demonstrate up to a fivefold reduction in energy consumption vs. a conventional gasoline-powered aircraft through the use of DEP technology [11]. This dramatic reduction in energy use is achieved through a confluence of increased motor, propulsive, and aerodynamic efficiencies. The build-up of these efficiencies is accomplished through SCEPTOR's spiral development process for the X-57. This 
includes tests of several variants of the same airframe, with each stable configuration known as an X-57 Configuration Modification, abbreviated as "Mod." The X-57 spiral development process includes four Mods as shown in Fig. 2.

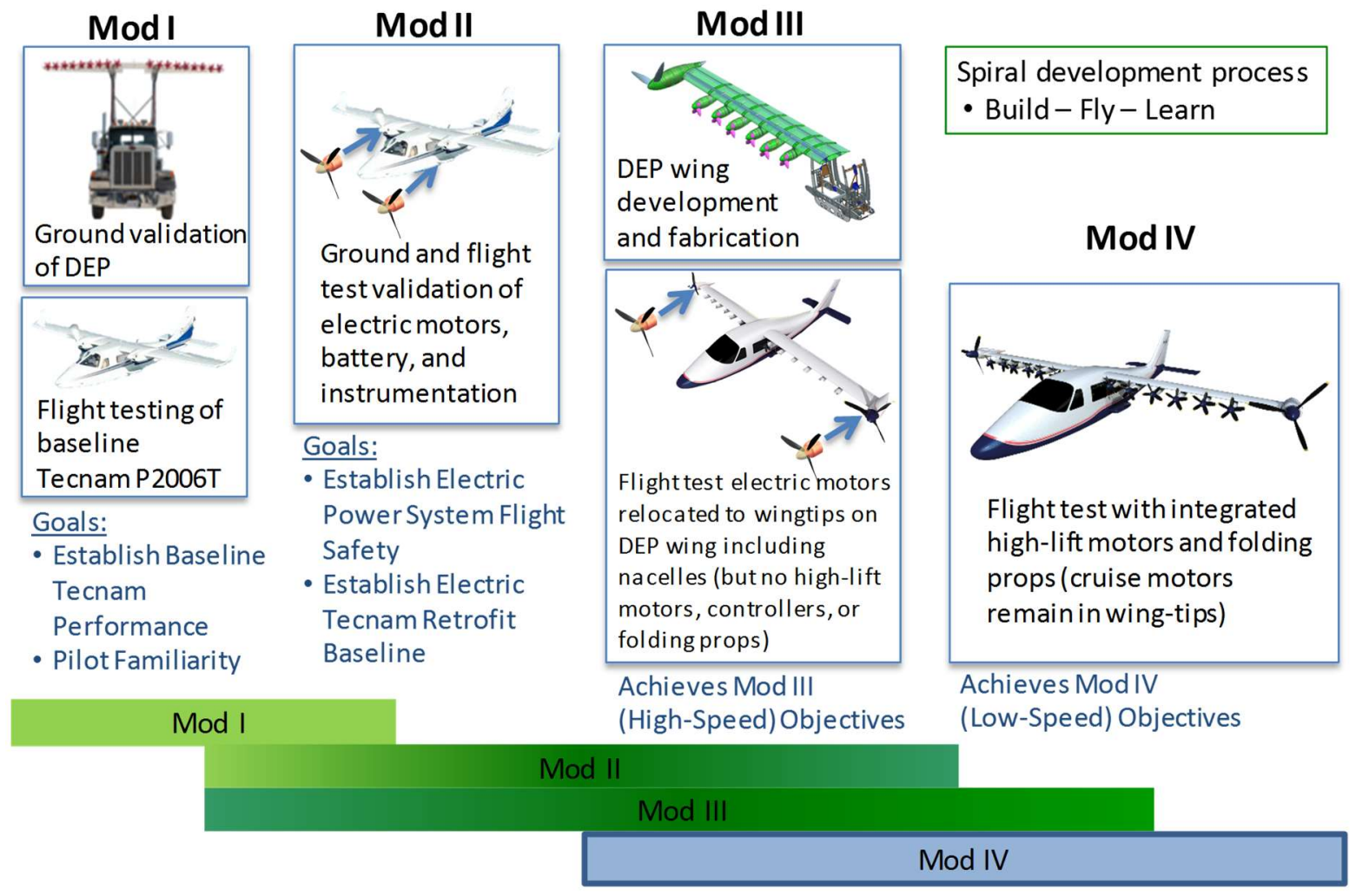

Fig. 2 X-57 spiral development through multiple "Mods" [11].

All X-57 variants (Mod I through Mod IV) involve a common airframe based on the commercially available Tecnam P2006T, a fixed-wing, four-person, twin-engine aircraft [12]. Tests involving Mod I established the baseline, gasoline-powered aircraft performance. X-57 Mod II replaces the two gasoline engines with electric motors and installs the X-57 high-voltage energy storage system (approximately $370 \mathrm{~kg}$ of batteries) in the aft cabin and cargo area. This Mod is used to verify the flight readiness of the primary traction propulsion system and to establish the overall change in powertrain efficiency. Mod III replaces the large P2006T wing with a much smaller wing suitable for DEP and moves the cruise motors tested on Mod II out to the wingtips. This configuration is used to show the high-speed cruise efficiency, including aerodynamic and aero-propulsive benefits. ${ }^{*}$ Finally, Mod IV represents the final configuration and is focused on showing that the low-speed performance with 12 additional "high-lift" motors and propellers is comparable to the original aircraft.

The X-57 is an excellent candidate for detailed design studies of a primary power system for FUELEAP since detailed design information exists regarding its high-voltage electrical system. Additionally, the large cabin area and provisions for the Mod II battery pack mass enable integration of hybrid-electric SOFC power system hardware. Though FUELEAP's development schedule is independent of current X-57 activities, each Mod represents a configuration that could be leveraged for a power system design study. Given that current X-57 activities (at the time of this paper) are focused on the airworthiness of X-57 Mod II, and the fact that Mod II represents a simpler retrofit on an existing aircraft, the FUELEAP team elected to use X-57 Mod II as the target for a detailed power system integration study. As such, the primary traction power system outlined in this paper will target the requirements associated with the X-57 Mod II configuration seen in Fig. 3. The new configuration is referred to as the X-57-F.

\footnotetext{
* In its final configuration, the X-57 Mod IV aircraft cruises only on the larger wingtip motors, which have a beneficial aerodynamic interference with the wingtip vortex. The remaining small motors are only used during takeoff and landing, with the propellers otherwise folded back cleanly against the high-lift nacelles in cruise. Hence, X-57 Mod III is used as a stepping-stone to Mod IV, by first testing the new wing without the Mod IV high-lift motors active.
} 


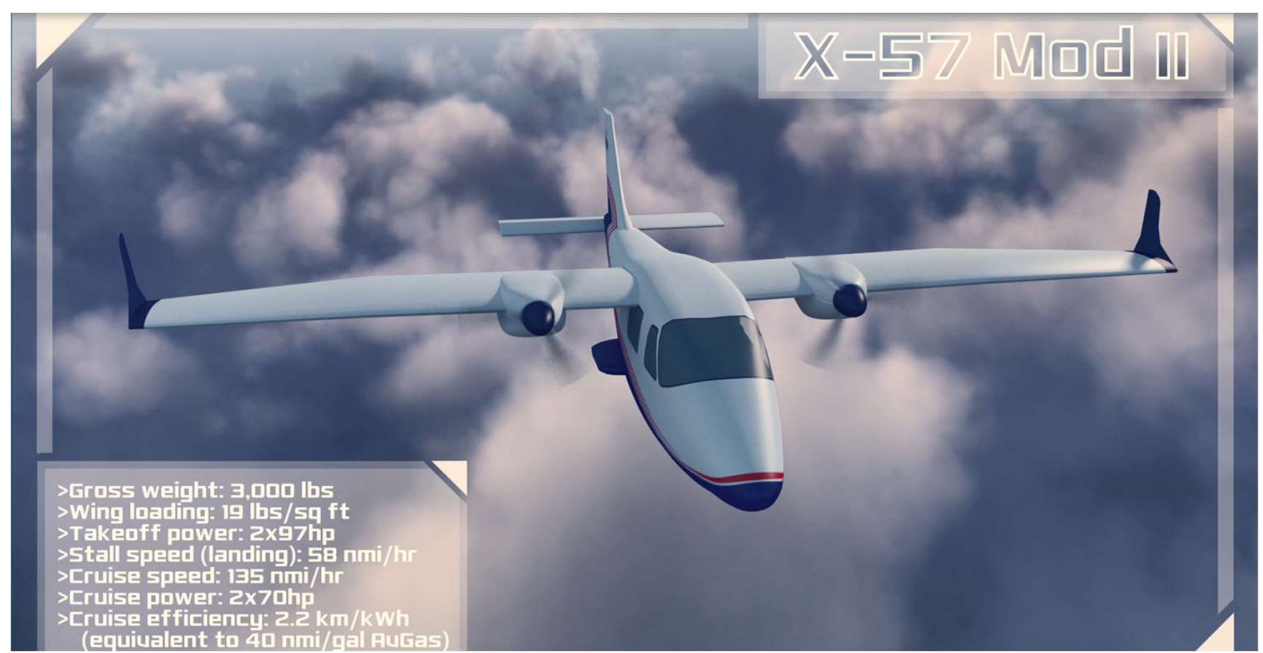

Fig. 3 X-57 Mod II configuration.

\section{X-57-F Feasibility Analysis}

Detailed design studies were performed to establish the feasibility of incorporating the FUELEAP hybrid-electric SOFC power system into the X-57-F (X-57 Mod II configuration). Initial scaling studies and conceptual estimates conducted by the FUELEAP team indicated that such a system could be used for primary power; however, the more detailed analyses served to increase confidence that the solution was feasible. These analyses also served to establish system performance and design information used for other FUELEAP activities, such as system safety analysis.

\section{A. Requirements}

The X-57-F is designed to the power and operating range requirements of the X-57 Mod II configuration. This includes operation within the X-57 Mod II flight envelope, which extends up to 15,000 ft above mean sea level (MSL) and a never-exceed speed of 172 knots calibrated airspeed (KCAS). ${ }^{\dagger}$ The X-57-F flight envelope, including overlays of typical climb and cruise conditions, is given in Fig. 4.

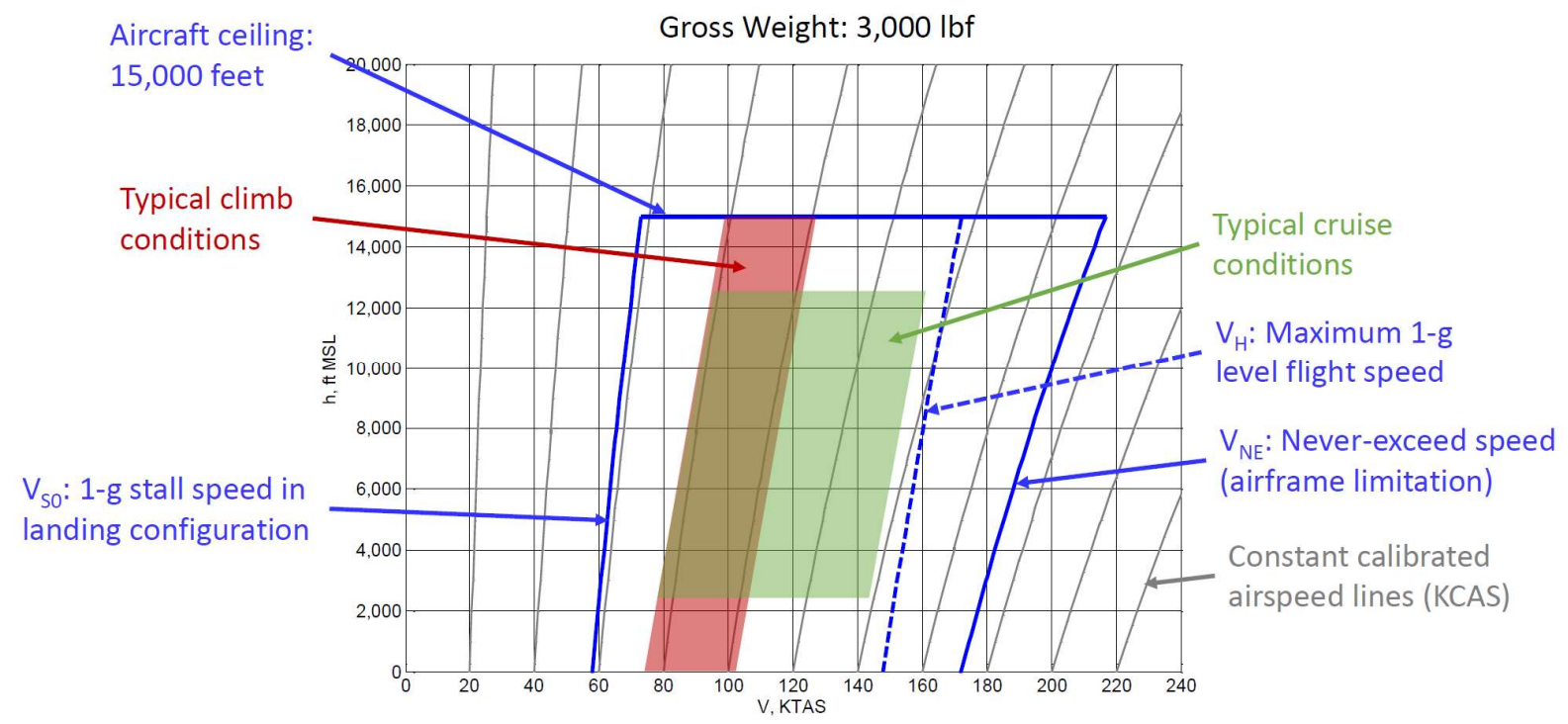

Fig. 4 X-57-F flight envelope.

\footnotetext{
† Though this paper generally uses the International System of Units (SI), some aircraft-level performance metrics, such as altitude and airspeed, are described in terms of feet and knots (nautical miles per hour) in accordance with conventions established by the International Civil Aviation Organization (ICAO).
} 
The propulsion on the X-57-F is provided by two Joby JM-X57K electric motors, each spinning a three-bladed MTV-7-A-152/64 constant-speed propeller [13][14]. The maximum available torque for these motors is $255 \mathrm{~N}-\mathrm{m}$, and the maximum speed of the propeller is $2700 \mathrm{RPM}$, bringing peak power output for takeoff to $72.1 \mathrm{~kW}$ for each electric propulsion unit. For thermal management reasons, the maximum continuous power (MCP) is limited to $60 \mathrm{~kW}$ per motor. Power for typical cruise conditions varies but is generally around $50 \mathrm{~kW}$ per motor. In addition, the X-57-F requires approximately $1 \mathrm{~kW}$ of additional power to run low-voltage aircraft systems, such as propeller pitch control motors, landing gear motors and pumps, avionics, instrumentation, and other ancillary accessories. Assuming a $92 \%$ efficient motor and controller architecture (slightly worse than predicted for the X-57 CDR [14]), the power requirements that drive the design are summarized in Table 1.

\section{Table 1 X-57-F Power System Sizing Requirements}

\begin{tabular}{|l|l|l|l|}
\hline Mission Phase & Duration & Motor Shaft Power, each & Power System Output $^{\ddagger}$ \\
\hline Takeoff/Initial Climb & $2-5 \mathrm{~min}$ & $72.1 \mathrm{~kW}$ & $158 \mathrm{~kW}$ \\
\hline Cruise Climb & $10 \mathrm{~min}$ & $60.0 \mathrm{~kW}$ & $131 \mathrm{~kW}$ \\
\hline Cruise & indefinite & $50.0 \mathrm{~kW}$ & $110 \mathrm{~kW}$ \\
\hline
\end{tabular}

In a hybrid-electric system, the power requirements listed in Table 1 do not need to come entirely from the fuel cell or associated balance of plant items. The power system architecture used for this study includes a high-voltage traction battery that can be used to handle periods of higher output, with the requirement that it can be recharged in 30 minutes of operation during the cruise portion of the mission. In addition, to ensure appropriate operation (including consistent performance after multiple cycles), the traction battery is required to be operated over a state of charge between $20 \%$ and $95 \%$ of capacity. The traction bus voltage of the hybrid-electric SOFC power system must be designed to be compatible with the X-57's existing electrical system, resulting in a range of 416-525 VDC. More details on the electrical system integration can be found in a companion paper by Papathakis et al. [5].

The X-57-F retains the X-57 maximum takeoff mass limit of $1364 \mathrm{~kg}$, as well as the forward and aft center of gravity (CG) limits of $26.5 \mathrm{~cm}$ and $41.5 \mathrm{~cm}$ from the project reference datum, respectively. These limits must take into account the mass of the entire hybrid-electric SOFC power system, including all balance of plant items. The batteries and battery control modules of the X-57 are located in the aft cabin, which includes the area where the two aft passengers and baggage were located in the P2006T fuselage. As such, this is the most appropriate area for the installation of the hybrid-electric SOFC power system. The approximate volume constraints associated with this location are shown in Fig. 5.
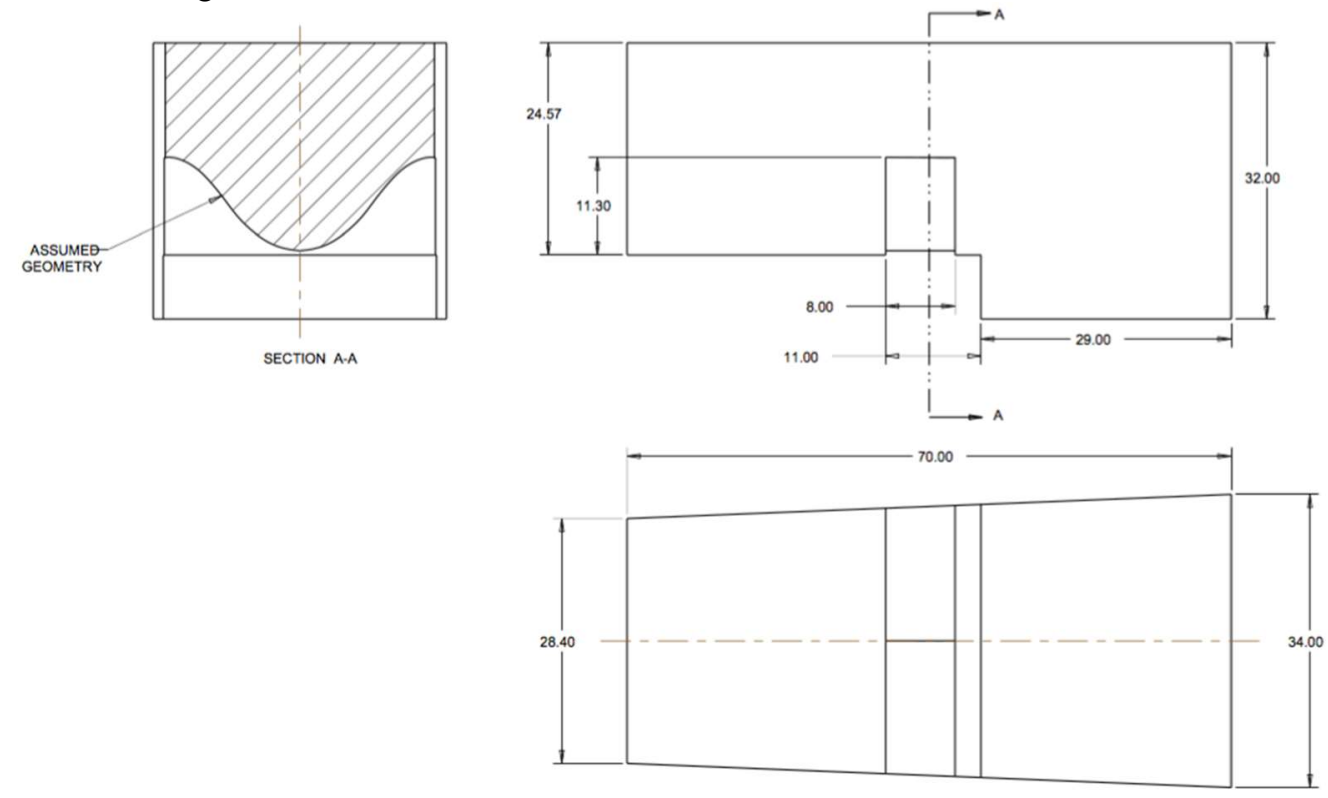

Fig. 5 Volume constraints levied on X-57-F hybrid-electric SOFC power system (dimensions in inches).

$\$$ Defined as $2 \times$ (shaft power / motor efficiency) $+1 \mathrm{~kW}$ for low-voltage aircraft systems. 


\section{B. Hybrid-Electric SOFC Power System}

The FUELEAP team developed the X-57-F power system over two Design/Analysis Cycles (DAC), dubbed DAC 1 and DAC 2. The DAC 1 architecture was based off the point-of-departure architecture developed for the initial 2016 study [3] and was capable of meeting the FUELEAP feasibility goals for specific power (>300 W/kg) and efficiency $(>60 \%)$. However, it required the use of a hot recycle blower (RCB) for the exhaust stream, which comes with development challenges - namely, reliable blower operation at temperatures of approximately $900^{\circ} \mathrm{C}$. The DAC 2 architecture focused on a less aggressive exhaust recycle approach. This resulted in a system that did not quite meet the feasibility targets for FUELEAP but still showed promise with additional development. A more detailed discussion of the trades conducted for the DAC 2 architecture are given in a companion paper by Stoia et al. [4]. The salient toplevel power system metrics for the DAC 1 and DAC 2 power system architectures are given in Table 2.

Table 2 FUELEAP Power System Metrics for X-57-F

\begin{tabular}{|c|c|c|}
\hline Metric & DAC 1 & DAC 2 \\
\hline Power system mass & $336 \mathrm{~kg}$ & $366 \mathrm{~kg}$ \\
\hline Power system electronics mass ${ }^{\S}$ & $18 \mathrm{~kg}$ & $18 \mathrm{~kg}$ \\
\hline Traction battery mass & $43 \mathrm{~kg}$ & $43 \mathrm{~kg}$ \\
\hline Total mass & $397 \mathrm{~kg}$ & $427 \mathrm{~kg}$ \\
\hline Max continuous power output, net & $120 \mathrm{~kW}$ & $120 \mathrm{~kW}$ \\
\hline Specific power, dry & $302 \mathrm{~W} / \mathrm{kg}$ & $281 \mathrm{~W} / \mathrm{kg}$ \\
\hline Efficiency, relative to LHV of fuel ${ }^{* *}$ & $62 \%$ & $55 \%$ \\
\hline
\end{tabular}

DAC 1 and DAC 2 were both sized to $120 \mathrm{~kW}$ of power output. This meets the cruise power output requirements of Table 1 while also providing $10 \mathrm{~kW}$ to charge the traction battery in the cruise configuration. A 30-minute cruise segment results in $5 \mathrm{kWh}$ of surplus energy that can be supplied to charge the traction battery. Considering the data in Table 1, the battery will be discharged during takeoff at $38 \mathrm{~kW}$ for up to five minutes, using $3.2 \mathrm{kWh}$, and will be discharged at $11 \mathrm{~kW}$ during the cruise climb for ten minutes, using $1.8 \mathrm{kWh}$ of output during cruise climb. Neglecting charge/discharge efficiency, takeoff and climb will use $5 \mathrm{kWh}$ of traction battery energy, resulting in a minimum battery capacity of $6.7 \mathrm{kWh}$ per the depth of discharge requirement. A $6.7 \mathrm{kWh}$ battery would have a C-rate (ratio of output power to capacity) of 5.7 during takeoff - significantly higher than is typical for most cells. As such, the traction battery needs to be sized by power output rather than by energy, based on a proprietary database of existing battery cells available to the team.

Other contingencies and events influence the sizing of other system components. For example, the electronics mass includes voltage converters for use during startup since the fuel cell components may not yet be at operating temperature and therefore not operating at rated voltage. The generator connected to the turbine shaft in the bottoming cycle is sized for a contingency condition - namely, the ability to output up to $50 \mathrm{~kW}$ in the event that the fuel cell completely shuts down. This, combined with the battery, provides enough performance for the aircraft to maintain level flight or shallow drift-down performance, giving the operator more options for an expedited landing. These and other situations are discussed in the companion papers by Papathakis et al. [5] and Woodham et al. [7].

The efficiency of the DAC 1 and DAC 2 power systems are referenced to the LHV of the input fuel. In both cases, the fuel selected was low-sulfur diesel, as the sulfur content of this fuel is low enough to be used in most SOFC systems after reformation without difficulty [3]. The LHV of diesel referenced in this study is estimated to be 43,500 $\mathrm{MJ} / \mathrm{kg}(12.1 \mathrm{kWh} / \mathrm{kg})$. The efficiency for both the DAC 1 and DAC 2 architectures was computed at the system MCP of $120 \mathrm{~kW}$ across a range of altitudes per the 1976 US Standard Atmosphere [15] at both the standard day and "hot day" (standard day $+25^{\circ} \mathrm{C}$ ) temperatures, as seen in Fig. 6. Later, more detailed models were executed for the DAC 2 architecture for partial power operation as seen in Fig. 7; the DAC 1 results in this paper use the (likely more pessimistic) full-power efficiency values for the computation of part-power results.

\footnotetext{
$\S$ For SOFC and bottoming turbine only; battery and X-57 traction bus connectors considered separately.

${ }^{* *}$ Referenced to maximum continuous power $(120 \mathrm{~kW}$ ) at 10,000 ft MSL in the 1976 U.S. Standard Atmosphere [15].
} 


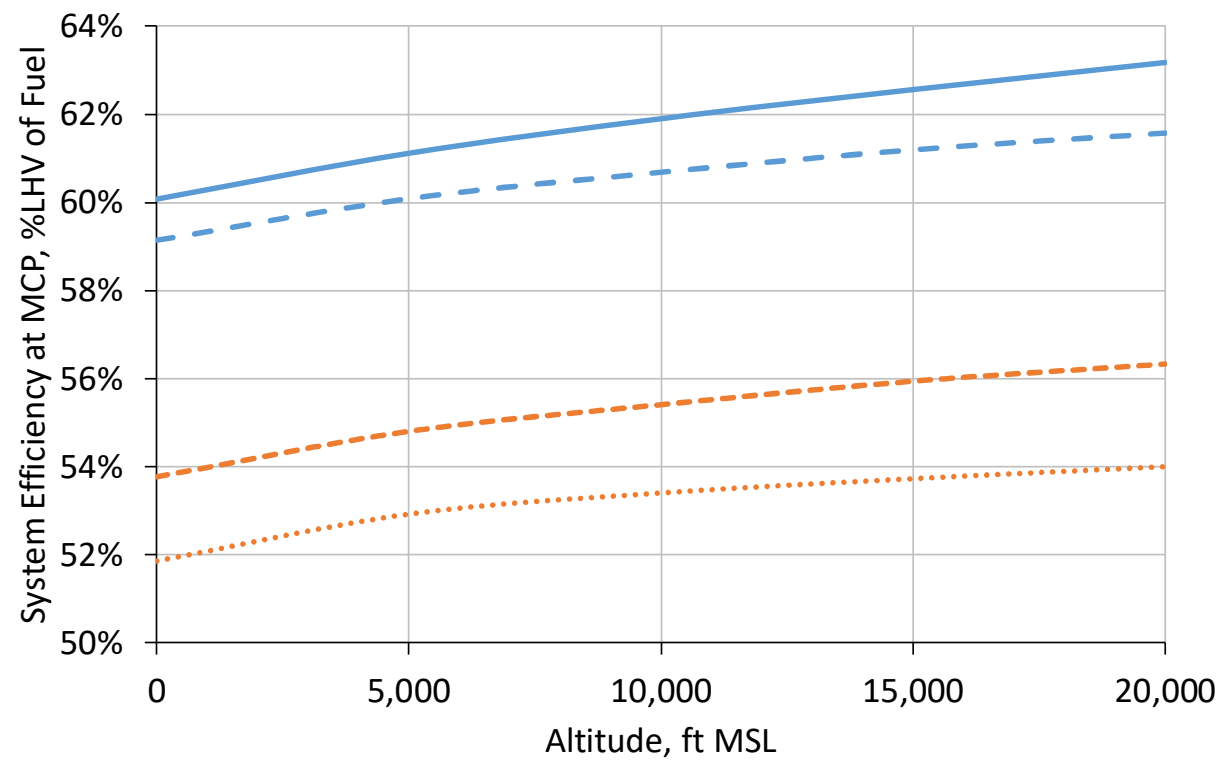

-DAC 1, standard day $\quad \cdots$ DAC 2, standard day
- - DAC 1, hot day $(+25 \operatorname{deg}$ C) $\cdots$ DAC 2, hot day $(+25$ deg C)

Fig. 6 Net power system efficiency vs. altitude for DAC 1 and DAC 2 architectures at MCP $(120 \mathrm{~kW})$.

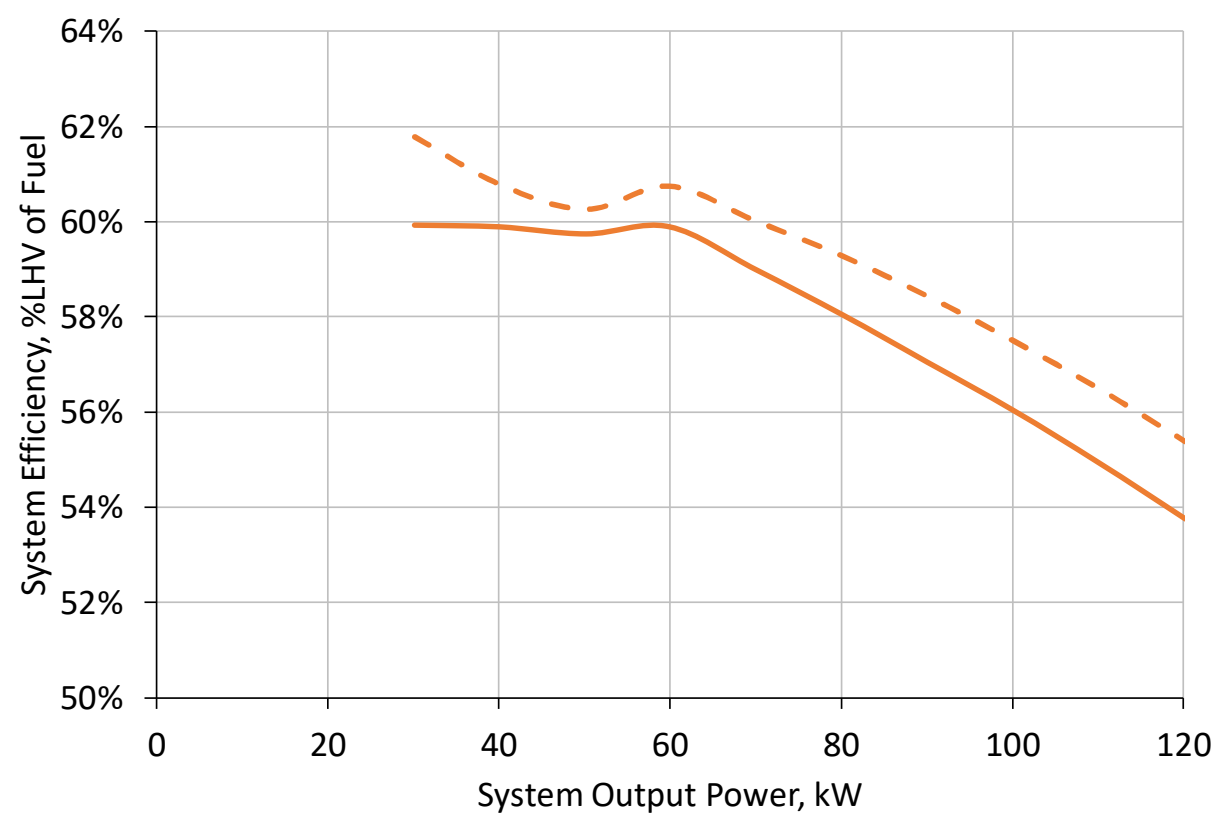

— $0 \mathrm{ft} \mathrm{MSL}$, standard day $\quad--10,000 \mathrm{ft}$ MSL, standard day

Fig. 7 Net system efficiency vs. net system output power, DAC 2 configuration.

The system efficiency curves in Fig. 7 indicate a fairly complex behavior that is representative of this configuration - a fairly constant increase in efficiency as power is reduced until approximately $50 \%$ power $(60 \mathrm{~kW})$. At this point, the control modes of the system change - instead of being able to capitalize on lower current density within the SOFC stack and potentially higher efficiency, combined with reduced demand on the air intake (and therefore compressor) loads, a waste gate within the turbomachinery needs to open to operate at lower powers. Estimation of part-power levels below $30 \mathrm{~kW}$ was not attempted as this is in a regime that does not support level flight; however, operation at 
these lower power levels is possible. In this case, the steam reformer is bypassed and the fuel reformation runs in catalytic partial oxidation mode, which is primarily used for startup operations. This is far less efficient (30-40\%) and has not been included in the mission analysis calculations to date, given that little flight time is spent in this regime.

\section{Volume and Mass/Balance}

The power system takes up a substantial amount of volume, given the number of different components and the required interconnectivity for nominal and contingency operations. The power system developed for FUELEAP, minus the traction battery and conversion electronics, is shown in Fig. 8 for both DAC 1 and DAC 2. The DAC 1 architecture minimally violated some of the volumetric requirements imposed on the system; the DAC 2 layout fit fully within the X-57-F architecture. An isometric view of the DAC 2 power system integrated into the X-57-F, including the traction battery and power distribution systems, is shown in Fig. 9.

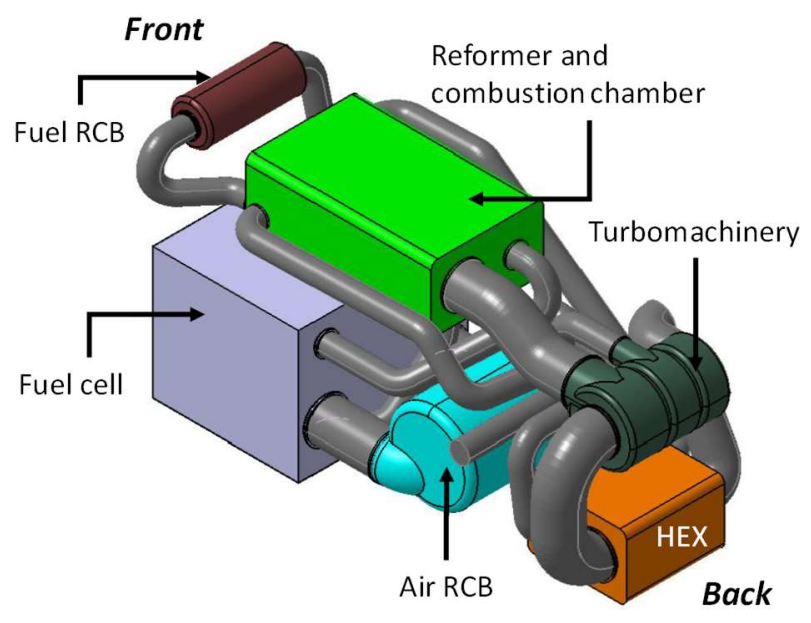

a) DAC 1 power system

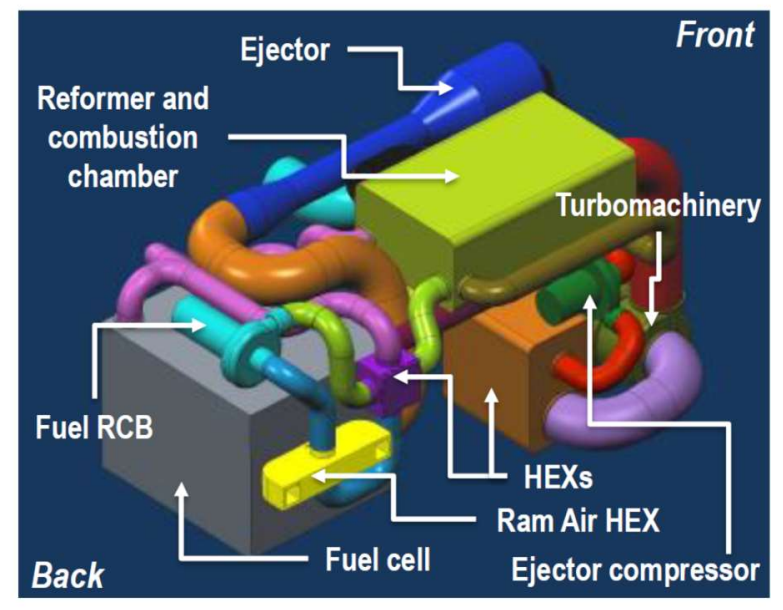

b) DAC 2 power system

Fig. 8 DAC 1 and DAC 2 layout for X-57-F power system (HEX: heat exchanger, RCB: recycle blower).

Additional ancillary mass estimates were made for the power system, not otherwise covered by the power system mass estimates provided in Table 2 . These included the power system mounting structure, traction battery mounting structure, traction battery ventilation system (required for single-cell thermal runaway events), traction battery wiring, traction bus wiring, and contactor pallet hardware. In addition, the team concluded that a firewall would likely be necessary between the crew cabin and the power system to meet safety standards. As such, the mass for a $0.38 \mathrm{~mm}$ thick stainless steel firewall was allocated to the aircraft. The additional mass of these structures and ancillary systems totaled $42 \mathrm{~kg}$ beyond the mass reported in Table 2. The corresponding gross mass properties of the X-57-F, along with comparison to other relevant aircraft, is given in Table 3. Here, "design operating mass, empty" includes everything except energy storage (fuel or batteries) and payload, and "energy storage mass" refers to the mass of the battery modules (X-57 Mod II) or fuel stored aboard the aircraft.

Table 3 Aircraft Mass Characteristics

\begin{tabular}{l|l|l|l} 
Aircraft & Design Operating Mass, Empty & Energy Storage Mass & Max. Takeoff Mass \\
\hline P2006 T & $916 \mathrm{~kg}$ & $0-140 \mathrm{~kg}$ & $1,233 \mathrm{~kg}$ \\
\hline X-57 Mod II & $861 \mathrm{~kg}$ & $372 \mathrm{~kg}$ & $1,364 \mathrm{~kg}$ \\
\hline X-57-F DAC 1 & $1,224 \mathrm{~kg}$ & $0-99 \mathrm{~kg}$ & $1,364 \mathrm{~kg}$ \\
\hline X-57-F DAC 2 & $1,254 \mathrm{~kg}$ & $0-69 \mathrm{~kg}$ & $1,364 \mathrm{~kg}$ \\
\hline
\end{tabular}

The X-57 Mod II and X-57-F configurations all have $41 \mathrm{~kg}$ of flight research instrumentation that is considered payload (i.e. separate from the required instrumentation for the pilot and normal flight operations). As such, the energy storage mass (allowable fuel) is limited by the maximum takeoff mass. The current estimates for the X-57 Mod II indicate that up to $90 \mathrm{~kg}$ of additional energy storage mass could be added without violating the maximum takeoff mass requirements. This "rubberized battery" comparison is discussed below. 


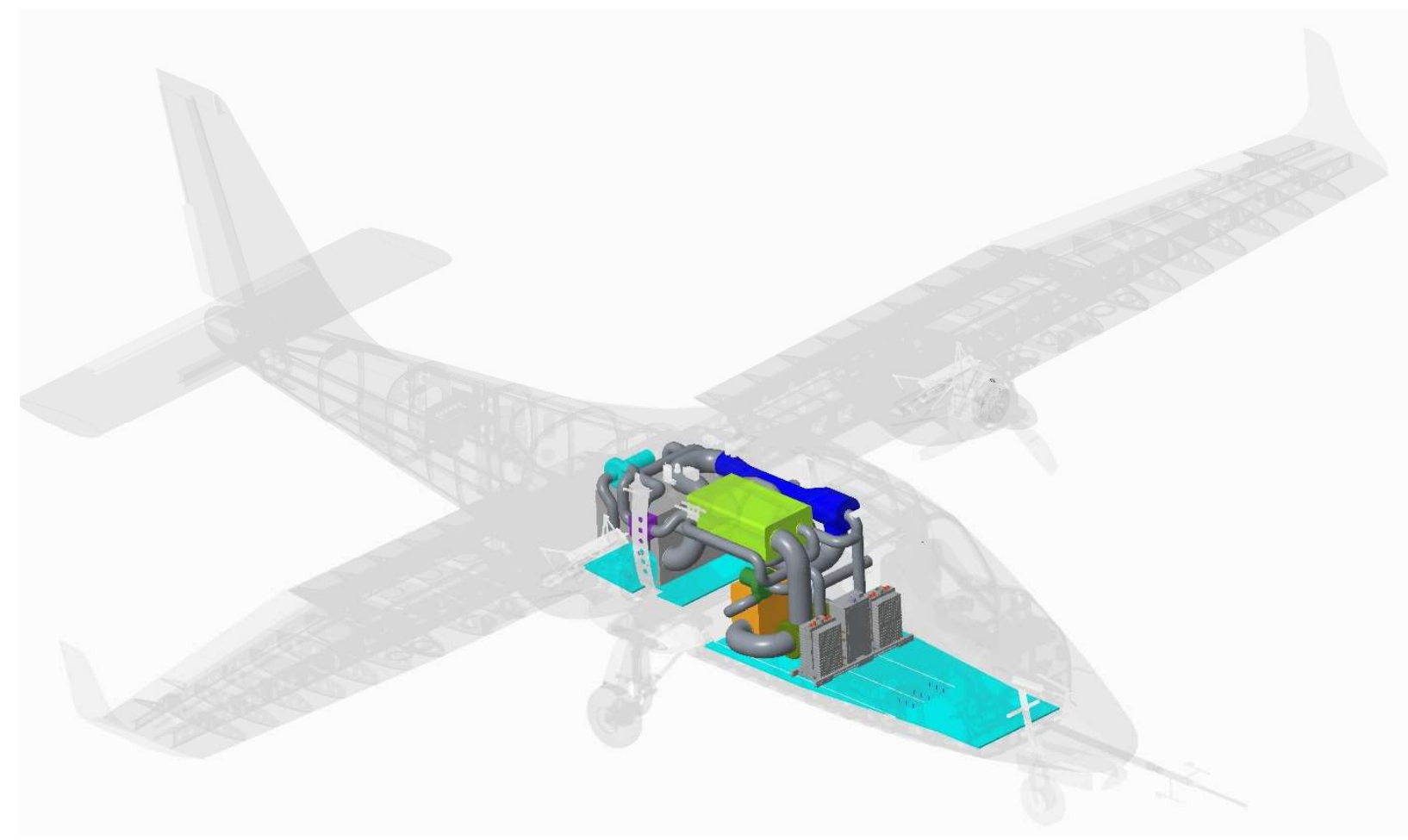

Fig. 9 DAC 2 power system installation in X-57-F.

\section{Performance}

The performance model of the X-57-F includes aerodynamic and power system models. The aerodynamic model is derived from the published cruise performance data given in the Airplane Flight Manual (AFM) for the Tecnam P2006T [12]. The performance data is given in terms of steady, level airspeed for given altitude and power settings. The net thrust of the aircraft at these power settings requires knowledge of the propeller efficiency; for this paper, the efficiency is assumed to be a constant $80 \%{ }^{\dagger \dagger}$. The X-57 Mod II and X-57-F configurations will have slightly different drag characteristics from the P2006T - notably, (1) the cowl design is different, with the X-57 motor cowl being much cleaner due to omission of most of the radiators necessary for the combustion engine on the P2006T, (2) the propeller performance of the P2006T and X-57 is slightly different (the P2006T propeller has two blades vs. three for the X-57, and the propeller diameter for the P2006T is $178 \mathrm{~cm}$ vs. $152 \mathrm{~cm}$ for the X-57), and (3) in the X-57-F configuration, there are additional drag sources in terms of some of the ram-air heat exchangers. For the purposes of this study, these differences were considered negligible. Fig. 10 shows the parabolic drag polar derived from this dataset and used for the performance model.

Models of all four aircraft from Table 3 were evaluated as part of this study. The propulsion model for the P2006T was built with data from the Rotax 912 Operator's Manual [16], which includes information on fuel flow rate vs. power production at various altitudes and temperatures. A constant net propeller efficiency of $80 \%$ was assumed to estimate net thrust production from the propellers (as it was for the propulsion models for all aircraft). This information was assembled into an "engine deck," consisting of thrust and fuel flow estimates for various combinations of Mach number, altitude, and power code (idle to peak power).

\footnotetext{
\# The SCEPTOR and FUELEAP teams have access to proprietary manufacturer information on the airframe and propeller; however, to enable public release of this paper, aerodynamic data and corresponding engine models were derived from publicly available sources and blanket assumptions (e.g. $80 \%$ net propeller efficiency).
} 


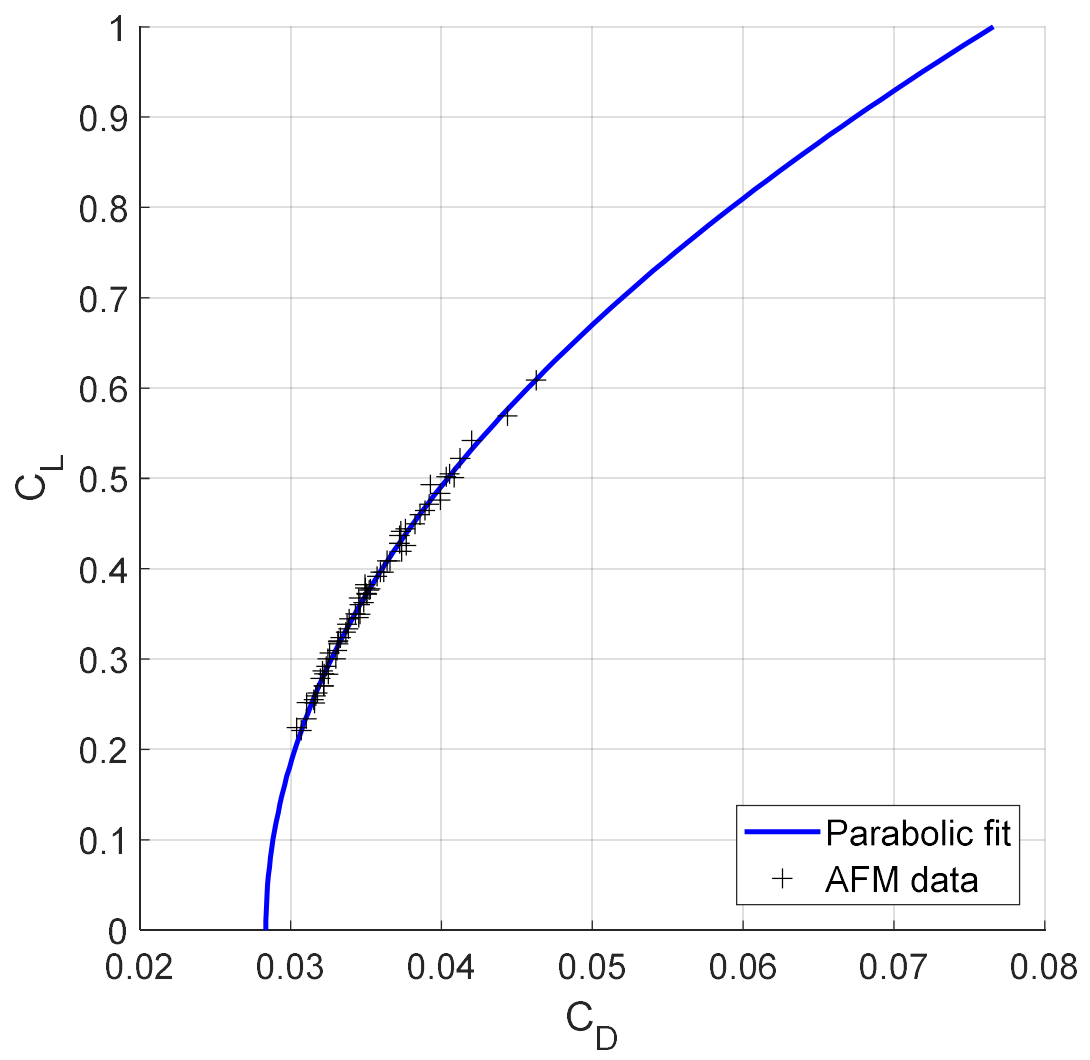

Fig. 10 Drag polar used for $X-57-F$ study $\left(C_{L}\right.$ : lift coefficient, $C_{D}$ : drag coefficient).

For the electrically powered X-57, the propulsion model accounted for the efficiency of the motor and inverter. The motor efficiency model was built from JM-X57K estimates [13][14]. The published efficiency maps are given in terms of torque and RPM, so an average value of motor efficiency was selected for a particular power range, bounded by the operational limits of the propeller and motor system (1700 to $2700 \mathrm{RPM}, 0$ to $255 \mathrm{~N}-\mathrm{m}$ of torque). A constant inverter efficiency of $98 \%$ was used for all power settings. Next, the efficiency of the fuel conversion in the SOFC power system was estimated from the DAC 1 and DAC 2 efficiency models shown in Fig. 6 and Fig. 7. Since partialpower efficiency data was not available for DAC 1, the efficiency was considered to only vary with altitude - likely a pessimistic assumption given that the DAC 2 architecture showed an increase in efficiency at partial power.

The battery-electric X-57 Mod II performance model was more challenging to develop. Since the X-57 Mod II consumes no fuel, but rather battery energy, some assumptions were made to allow the X-57 Mod II performance model to use legacy, fuel-burning analysis tools. The battery power draw was converted into fuel flow by dividing shaft power by the product of motor and inverter efficiency for the particular operating point in the engine deck, and then dividing the result by the LHV of diesel. This created a (low) "fuel flow" that could be input into the engine deck. The baseline fuel mass of the X-57 Mod II was estimated by converting the battery mass to energy, per the specific energy of the fully burdened X-57 Mod II battery pack, defined as the energy available between the state of charge from $95 \%$ to $20 \%$ at a representative discharge rate. This resulted in a specific energy of approximately $130 \mathrm{Wh} / \mathrm{kg}$.

The mission performance model integrated information from the drag polar and engine decks. NASA's Flight Optimization System (FLOPS) [17] was used to conduct this analysis. true airspeed (KTAS) at a target altitude of $8,000 \mathrm{ft}$ MSL was used to generate different mission profiles. This is representative of a typical high-speed cruise value for a P2006T. The maximum fuel volume was constrained to the P2006T fuel volume limit of 200 liters. The X-57 Mod II model was evaluated with a "rubberized" battery that used up all extra available mass in the aircraft to establish payload-range performance. The resulting payload-range performance of these four aircraft is shown in Fig. 11.

$\$$ The reference in this paper directs users to the publicly available FLOPS v.9, whereas the results in this study were calculated using FLOPS 8.23, which is currently only available to NASA employees. The results would likely be identical given that the particular models constructed for this paper do not use features of the FLOPS software that are only available to NASA employees. 


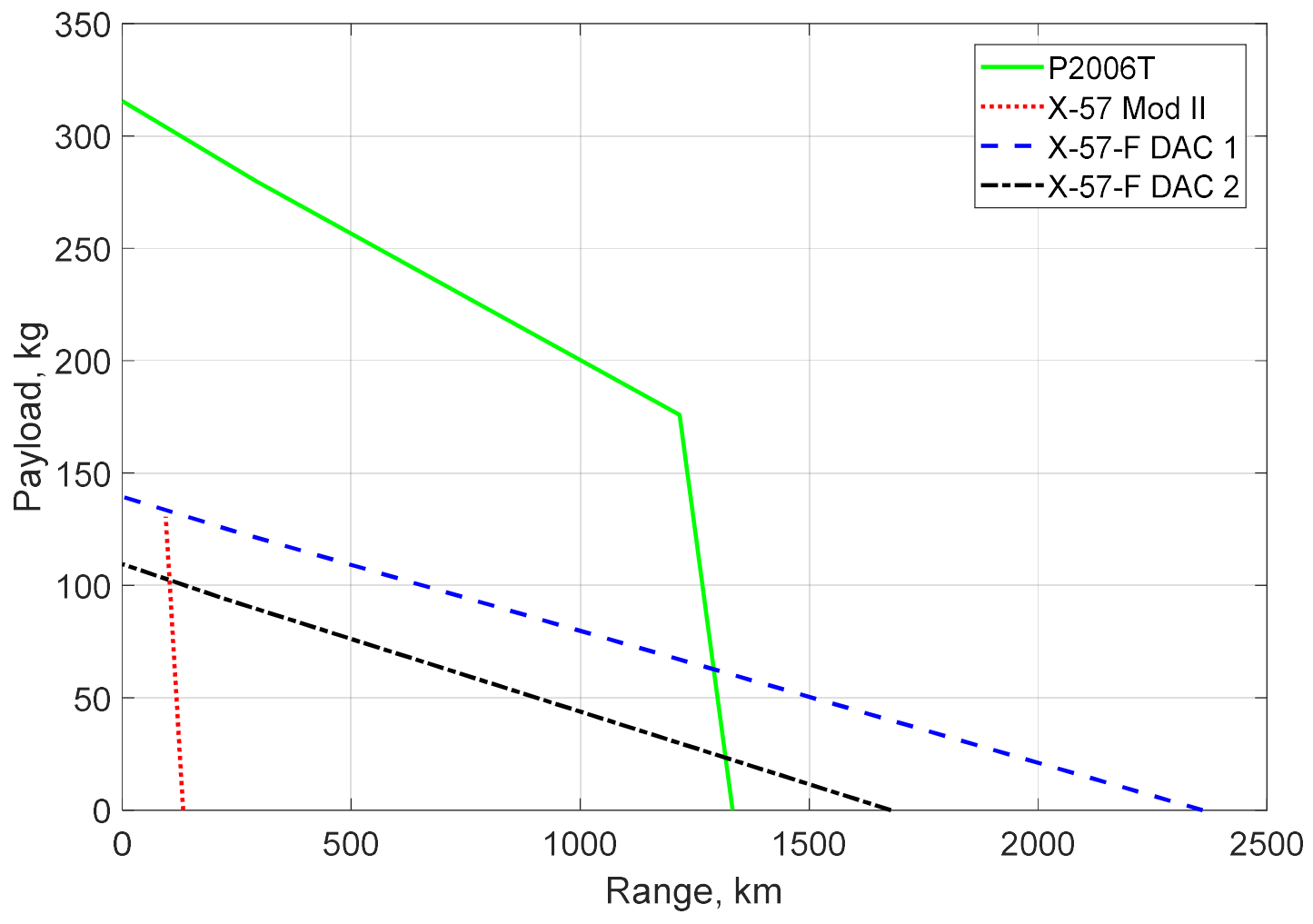

Fig. 11 Payload-range performance estimates for relevant aircraft in X-57-F study.

\section{E. Discussion}

A few limitations of this approach are apparent. The initial cruise segment will consume slightly more fuel than indicated in the DAC 1 and DAC 2 engine decks since the power system also needs to recharge approximately $5 \mathrm{kWh}$ into the traction battery. Given that this energy to recharge is generally not much more than one percent of the useful energy produced by the system for all but the shortest missions in Fig. 11, it will not serve as a significant bias to the results. Converting the X-57 Mod II to burn "fuel" instead of energy introduces some error. The fuel-burning aircraft model gets lighter during the mission, reducing drag. This is of negligible importance to the mission analysis, given that the simulated "fuel" mass for the battery-powered X-57 Mod II ranges from 3.9 to $5.3 \mathrm{~kg}$ for the data shown in Fig. 11, representing less than a half percent of aircraft weight.

At first blush, the payload-range performance in Fig. 11 does not appear to be compelling for the battery-electric X-57 Mod II, or the hybrid-electric X-57-F DAC 1 and DAC 2 configurations. However, it also does not tell the complete story. First, unlike the P2006T, the X-57 series of aircraft are not intended to be production vehicles with a broad transportation and training mission. Rather, the X-57 is a flight demonstrator for DEP technology, designed to be a compromise of low cost vs. high research value. Hence, a purpose-built battery-electric aircraft, or hybrid-electric aircraft, designed to be competitive with the P2006T may look significantly different. A "clean sheet" design would maximize the benefits associated with airborne electric propulsion, such as alluded to by Stoll and Veble [18].

The X-57 variants have the potential to introduce lower emissions. Table 4 shows the energy used for each of the four aircraft on a $75 \mathrm{~km}$ mission, a $200 \mathrm{~km}$ mission, and a 1,000 km mission. These values were derived from data in the aforementioned FLOPS models, again with a cruise target of $135 \mathrm{KTAS}$ at 8,000 $\mathrm{ft}$ MSL. The payload was kept constant at the X-57 Mod II research instrumentation mass of $41 \mathrm{~kg}$ (perhaps not a useful payload, but used to establish consistency). The X-57 Mod II energy use is only shown for the $75 \mathrm{~km}$ mission since it does not have the mass available to for a battery with enough energy to complete the $200 \mathrm{~km}$ or $1,000 \mathrm{~km}$ missions at the target altitude and speed. The energy use of the X-57 Mod II is also given in terms of the total input energy required to charge the batteries based on the U.S. average electrical grid generation efficiency of 34\% [19]. To a first order, the total input energy can be used as a surrogate for emissions, as described in a companion paper [1]. The energy use of the X-57-F architectures is adjusted upward by $8 \mathrm{kWh}$ and $9 \mathrm{kWh}$ for the DAC 1 and DAC 2 architectures, respectively, to account for increased energy use due to charging the hybrid battery. 
Table 4 Energy Use for Relevant Aircraft in X-57-F Study at Constant Mission Range, 41 kg Payload

\begin{tabular}{|l|l|l|l} 
Aircraft & Energy use, 75 km & Energy use, 200 km & Energy use, 1,000 km \\
\hline P2006T & $95 \mathrm{kWh}$ & $253 \mathrm{kWh}$ & $1,275 \mathrm{kWh}$ \\
\hline X-57 Mod II & $36 \mathrm{kWh}(106 \mathrm{kWh})$ & N/A & N/A \\
\hline X-57-F DAC 1 & $67 \mathrm{kWh}$ & $155 \mathrm{kWh}$ & $726 \mathrm{kWh}$ \\
\hline X-57-F DAC 2 & $75 \mathrm{kWh}$ & $173 \mathrm{kWh}$ & $807 \mathrm{kWh}$ \\
\hline
\end{tabular}

In addition to potential emissions savings, the $\mathrm{X}-57$ variants also have the potential for reduced energy costs. The mission energy costs are shown in Table 5. These are derived from the January 2018 energy cost data from the Alternative Fuels Data Center (AFDC) [20], multiplied by the aircraft mission energy use from Table 4. The P2006T energy use is priced as gasoline at $\$ 0.075$ per $\mathrm{kWh}(\$ 2.50$ per gallon of gasoline equivalent energy or GGE, the native unit used by the AFDC), the X-57 Mod II energy use is priced to residential electricity at $\$ 0.123$ per $\mathrm{kWh}(\$ 4.11$ per GGE), and the X-57-F energy use is priced to diesel fuel at $\$ 0.079$ per $\mathrm{kWh}$ ( $\$ 2.63$ per GGE).

Table 5 Energy Cost for Relevant Aircraft in X-57-F Study at Constant Mission Range, 41 kg Payload

\begin{tabular}{|l|l|l|l|} 
Aircraft & Energy cost, $75 \mathbf{~ k m}$ & Energy cost, 200 $\mathbf{~ k m}$ & Energy cost, 1,000 $\mathbf{~ k m}$ \\
\hline P2006T & $\$ 7.09$ & $\$ 18.90$ & $\$ 95.37$ \\
\hline X-57 Mod II & $\$ 4.45$ & N/A & N/A \\
\hline X-57-F DAC 1 & $\$ 5.29$ & $\$ 12.23$ & $\$ 57.18$ \\
\hline X-57-F DAC 2 & $\$ 5.93$ & $\$ 13.65$ & $\$ 63.51$ \\
\hline
\end{tabular}

The energy use and cost data highlight the potential benefits of the hybrid-electric SOFC power system used in the X-57-F configurations. Compared to the gasoline-powered P2006T, the DAC 1 configuration reduces the operating cost by nearly the same amount as the purely electric X-57 Mod II on the short-range mission, and by up to $40 \%$ on the longer-range missions. The less aggressive DAC 2 architecture still provides significant energy cost savings, ranging from $16 \%$ to $33 \%$ less than the $\mathrm{P} 2006 \mathrm{~T}$ depending on mission length. The overall energy use is lower for the DAC 1 and DAC 2 designs than either the P2006T or the X-57 Mod II, in the latter case if one considers the total energy consumed by the electrical generation processes on the average 2016 U.S. grid.

\section{Conclusion}

NASA's FUELEAP project was initiated in 2016 to "establish the feasibility of an integrated heavy-fuel hybridelectric SOFC power system as a transformational source of aviation power." The technical metrics associated with feasibility were to show that such a system could be designed with at least $75 \mathrm{~kW}$ of net output, at a specific power of $300 \mathrm{~W} / \mathrm{kg}$, and an efficiency of greater than $60 \%$ referenced to the lower heating value of the input fuel. FUELEAP is using a three-pronged approach to show that such a system could be developed: testing of representative SOFC hardware in flight-like environments to demonstrate technological maturity of key components, detailed design of a hybrid-electric SOFC power system for generation of primary propulsive power for a representative aircraft, and conceptual design of an auxiliary power system for a larger aircraft. This paper addressed the second aspect of the FUELEAP project by developing detailed geometry and performance models for a flight demonstrator concept.

The FUELEAP team leveraged data on NASA's X-57 "Maxwell" all-electric flight demonstrator to conduct this analysis. The X-57 Mod II configuration, with over $370 \mathrm{~kg}$ of batteries and two $72 \mathrm{~kW}$ electric motors, was reimagined with a FUELEAP hybrid power system, and dubbed the X-57-F. The hybrid-electric SOFC power system was capable of $120 \mathrm{~kW}$ of net output at maximum continuous power and $158 \mathrm{~kW}$ of peak power for takeoff using a small, high-voltage traction battery. Two different designs were scrutinized. The X-57-F DAC 1 configuration used a power system (including traction battery) capable of exceeding all feasibility criteria $-120 \mathrm{~kW}$ net output, $302 \mathrm{~W} / \mathrm{kg}$ specific power, and $62 \%$ efficiency referenced to input diesel fuel. To meet these goals, DAC 1 required the use of recycle blowers for hot gases that could exceed $900^{\circ} \mathrm{C}$. Although these technologies exist, additional development would be needed to achieve the reliability, mass, and performance requirements associated with routine, passengercarrying airborne operations. Given that this may be a difficult challenge, the team developed the X-57-F DAC 2 configuration, which resulted in performance slightly below the stated FUELEAP feasibility goals $-120 \mathrm{~kW}$ net output, $281 \mathrm{~W} / \mathrm{kg}$ and $55 \%$ efficiency. These values are obtainable without the development risk associated with hot recycle blowers.

The mission capability of the X-57-F was scrutinized relative to the capability of the Tecnam P2006T, which is the gasoline-powered baseline aircraft for the X-57, and the battery-powered X-57 Mod II. This analysis showed that 
from a mission capability, energy cost, and energy use standpoint, the X-57-F DAC 1 and DAC 2 variants were at the very least competitive with the P2006T and X-57 Mod II. Overall, the design exercise in this paper concluded that the hybrid-electric SOFC power system can meet FUELEAP's feasibility goals and has the potential to be competitive amongst alternatives for airborne primary propulsive power generation.

A known limitation of this study is the focus on the retrofit of a single aircraft configuration. Design of successful aircraft requires careful consideration and balance of aerodynamics, propulsion, structures, control, operations, and many other disciplines. It is rare that a major shift in one discipline, such as a complete change in the type of propulsion system, results in little change to the other disciplines to create a balanced aircraft design. Yet, that approach was necessitated by the scope and resource limitations of this study. The results of this study are compelling enough to suggest that a more holistic look at the impact of FUELEAP technologies on aircraft design is warranted.

\section{Acknowledgments}

This work was funded by NASA's Aeronautics Research Mission Directorate (ARMD) under the Transformational Aeronautics Concepts Program. In particular, this research was part of the Fostering Ultra-Efficient, Low-Emitting Aviation Power (FUELEAP) subproject of the Convergent Aeronautics Concepts Project. Though this particular research paper was not directly supported by X-57, much data from the X-57 effort, funded under the NASA ARMD Integrated Systems Research Program Flight Demonstrations and Capabilities Project, is used to support FUELEAP. The information on the hybrid-electric SOFC power system design was developed by the Boeing Co. under task order NNL17AA45T, "Fostering Ultra-Efficient, Low Emitting Aviation Power (FUELEAP)," of the NASA Langley Research Center Basic and Applied Aerospace Research and Technology (BAART) contract NNL16AA04B. The authors thank NASA for their support of FUELEAP and thank all of FUELEAP's industry partners for their contributions.

\section{References}

[1] Borer, N. K., "Catalyzing Disruptive Mobility Opportunities through Transformational Aviation Power," AIAA AVIATION Forum, Atlanta, GA, June 2018.

[2] National Academies of Sciences, Engineering, and Medicine, Commercial Aircraft Propulsion and Energy Systems Research: Reducing Global Carbon Emissions," That National Academies Press, Washington, D.C., 2016. doi: 10.17226/23490

[3] Stoia, T. R., Atreya, S., O’Neil, P., Balan, C., "A Highly Efficient Solid Oxide Fuel Cell Power System for an All-Electric Commuter Airplane Flight Demonstrator," AIAA-2016-1024, AIAA SciTech 2016, San Diego, CA, January 2016.

[4] Stoia, T. R., Balan, C., Atreya, S., Mata, M., O’Neil, P., "Solid Oxide Fuel Cell - Steam Reformation Power System Configuration Options for an All-Electric Commuter Airplane Flight Demonstrator," AIAA AVIATION Forum, Atlanta, GA, June 2018.

[5] Papathakis, K. V., Shnarr, O. C., Lavelle, T. M., Borer, N. K., Stoia, T., Atreya, S., "Integration Concept for a Hybrid-Electric Solid-Oxide Fuel Cell Power System into the X-57 'Maxwell'," AIAA AVIATION Forum, Atlanta, GA, June 2018.

[6] Goldsby, J. C., Jakupca, I. J, Green, R. D., Demattia, B. T., Loyselle, P. L., "Evaluation Studies of an 800 W Solid OxideBased Fuel Cell Stack for Electrical Power in Aviation," AIAA AVIATION Forum, Atlanta, GA, June 2018.

[7] Woodham, K. P., Graydon, P. J., Borer, N. K., Papathakis, K. P., Stoia, T., Balan, C., "FUELEAP Model-Based System Safety Analysis," AIAA AVIATION Forum, Atlanta, GA, June 2018.

[8] Gough, K. M., Phojanamongkolkij, N., "Employing Model-Based Systems Engineering (MBSE) on a NASA Aeronautics Research Project: A Case Study," AIAA AVIATION Forum, Atlanta, GA, June 2018.

[9] Borer, N. K., Nickol, C. L., Jones, F. P., Yasky, R. J., Woodham, K., Cagle, C. M., Fell, J. S., Litherland, B. L., Loyselle, P. L., Provenza, A. J., Kohlman, L. W., Samuel, A. G., "Overcoming the Adoption Barrier to Electric Flight," AIAA-20161022, AIAA SciTech 2016, San Diego, CA, January 2016.

[10] National Aeronautics and Space Administration, "Five New Ideas to be Explored by NASA Aeronautics Teams," accessed 15 May 2018.

[11] Borer, N. K., Patterson, M. D., Viken, J. K., Moore, M. D., Clarke, S., Redifer, M., Christie, R., Stoll, A., Dubois, A., Bevirt, J., Gibson, A., Foster, T., Osterkamp, P., "Design and Performance of the NASA SCEPTOR Distributed Electric Propulsion Flight Demonstrator," AIAA-2016-3920, 16th AIAA Aviation Technology, Integration, and Operations Conference, AIAA AVIATION Forum, Washington, D.C., June 2016. doi: 10.2514/6.2016-3920

[12] Costruzioni Aeronautiche Tecnam S.r.1, "P2006T - Aircraft Flight Manual,” Doc. No. 2006/044, 4th Ed - Rev. 0, Italy, 2015.

[13] Dubois, A., van der Geest, M., Bevirt, J., Clarke, S., Christie, R. J., Borer, N. K., "Design of an Electric Propulsion System for SCEPTOR's Outboard Nacelle," AIAA-2016-3925, $16^{\text {th }}$ AIAA Aviation Technology, Integration, and Operations Conference, AIAA AVIATION Forum, June 2016. doi: 10.2514/6.2016-3925

[14] National Aeronautics and Space Administration, "X-57 Critical Design Review," Edwards, CA, November 2016. Available at: https://www.nasa.gov/X-57/technical/index.html, accessed 8 May 2018. 
[15] National Oceanic and Atmospheric Administration, National Aeronautics and Space Administration, United States Air Force, “U. S. Standard Atmosphere, 1976," NOAA-S/T 76-1562 / NASA-TM-X-74335, Washington, D.C., October 1976. Available at: https://ntrs.nasa.gov/search.jsp?R=19770009539, accessed 16 May 2018.

[16] BRP-Powertrain GmbH\&Co, "Operators Manual for ROTAX ${ }^{\circledR}$ Engine Type 912 Series,” ref. no. OM-912, Austria, 2015.

[17] National Aeronautics and Space Administration, "Flight Optimization System (FLOPS) Software v.9," NASA Software Catalog, 2018. Available at: https://software.nasa.gov/software/LAR-18934-1, accessed 17 May 2018.

[18] Stoll, A. M. and Veble Mikic, G., "Design Studies of Thin-Haul Commuter Aircraft with Distributed Electric Propulsion," AIAA 2016-3765, 16th AIAA Aviation Technology, Integration, and Operations Conference, AIAA AVIATION Forum, Washington, D.C., June 2016. doi: 10.2514/6.2016-3765

[19] Lawrence Livermore National Laboratory, "Energy Flow Charts: Charting the Complex Relationships among Energy, Water, and Carbon," https://flowcharts.llnl.gov, accessed 16 November 2017.

[20] U.S. Department of Energy, Alternative Fuels Data Center, "Fuel Prices," U.S. Department of Energy, Alternative Fuels Data Center, "Fuel Prices," U.S. Department of Energy, Alternative Fuels Data Center, "Fuel Prices," https://www.afdc.energy.gov/fuels/prices.html, accessed 8 May 2018. 